\title{
Timotein siemensadon korjuun varmistaminen
}

Oiva Niemeläinen ja Markku Niskanen

MTT, Kasvintuotannon tutkimus, E-talo, 31600 Jokioinen

\section{Tiivistelmä}

Suomessa timotein siemensato korjataan suoralla leikkuupuinnilla. Tällöin osa siemensadosta menetetään varisemistappioina kun siemeniä alkaa varista tähkän latvasta ennen kuin tähkän tyviosa on tuleentunut leikkuupuintivalmiiksi. Tanskassa timotei korjataan niittämällä kasvusto ensin luo'olle, jonka jälkeen kuivunut luoko puidaan. Luo'olle niitetty kasvusto "jälkituleentuu" ja se ei ole niin altis tuulen ja sateen varistamisvaikutukselle kuin pystyssä oleva kasvusto. Suomeenkin on hankittu ensimmäisiä luo'olle niittolaitteita. Ylistaron tutkimusasemalla toteutettiin vuosina 2006 ja 2007 koe, jossa selvitettiin luo'olle niiton vaikutusta timotein siemensadon korjuussa. Tutkimuksessa selvitettiin onko mahdollista kohottaa ja varmistaa timotein siementuotannossa hehtaarisatoja luo'olta puinnilla. Kokeessa oli viisi koejäsentä: 1) Aikainen leikkuupuinti (puinti ajankohtana 1), 2) Normaali leikkuupuintiajankohta (6 päivää edellisestä), 3) Niitto luo'olle ajankohtana 1 ja puinti sängeltä 3-6 päivän kuluttua, 4) Niitto luo'olle ajankohtana 1 ja puinti sängeltä 6-9 päivän kuluttua, 5) Puinti hellävaraisin säädöin ajankohtana 1 ja uudelleen puinti 6 päivää ensimmäisestä puinnista. Varhaisen puinnin/luo'olle niiton ajankohdat olivat 15.8.2006 ja 20.8.2007. Vuosien välillä oli huomattava satoero. Vuonna 2006 saatiin normaalilla leikkuupuinnilla $502 \mathrm{~kg} / \mathrm{ha}$ ja vuonna $2007274 \mathrm{~kg} / \mathrm{ha}$. Vuonna 2006 suurin sato saatiin aikaisella ankaralla leikkuupuinnilla $673 \mathrm{~kg} / \mathrm{ha}$. Se erosi tilastollisesti merkitsevästi muista koejäsenistä joiden sato vaihteli välillä $502 \mathrm{~kg} / \mathrm{ha} \mathrm{ja} 538 \mathrm{~kg} / \mathrm{ha}$. Vuonna 2007 koejäsenten 2, 3, ja 4 sadon määrä ei eronnut merkitsevästi tosistaan $(274,292$ ja $240 \mathrm{~kg} / \mathrm{ha})$, mutta koejäsenten 1 ja 5 sato jäi merkitsevästi alhaisemmaksi 192 ja 164 kg/ha. Sekä aikaisessa että normaalin aikaan tehdyssä leikkuupuinnissa siemenkoko oli v. 2007 merkittävästi alhaisemmaksi kuin muissa koejäsenissä. Vuonna 2007 puintikosteus oli merkitsevästi alhaisempi kolme päivää luo'olla kuivatetussa kasvustossa $16,4 \%$ kuin 2:ssa $24,0 \%$, joka myös erosi merkitsevästi muiden koejäsenten puintikosteudesta $129,2 \%, 4$ 28,3\% ja 5 27,8\%. Korjuuajan sateisuus v. 2007 vaikutti tuloksiin. Tutkimus antoi viitteitä, että timotein siemenkasvuston luo'olle niitolla voidaan saavuttaa tietyissä olosuhteissa etua sadon määrässä ja kuivatustarpeessa normaaliin suoraan leikkuupuintiin verrattuna. Tutkimukset varsinaisella korjuukalustolla ja erilaisissa korjuuolosuhteissa ja kasvustoissa ovat tarpeen tarkempien ohjeistusten tekemiseksi. Myös normaali suora leikkuupuinti antoi tässä kokeessa hyvän tuloksen käytettyihin luo'olta puintikäsittelyihin verrattuna. Puinti kahteen kertaan ei lisännyt satoa tässä tutkimuksessa.

Asiasanat: karheelle niitto, puinti, puintitekniikka, sadonkorjuu, siementuotanto, timotei. 


\section{Johdanto}

Suomen viljelyolosuhteet ovat suotuisat timotein siemenviljelylle, mutta hehtaarisatojen vaihtelu on ollut huomattavan suurta vuosien välillä. Vuosina 1992, 1993 ja 2003 keskisadot olivat niukasti yli $200 \mathrm{~kg} / \mathrm{ha}$, mutta vuosina 1995, 1996 ja 2006 keskisadot olivat noin $600 \mathrm{~kg} / \mathrm{ha}$ siementuotannon vuosivaihtelutilastoista (Evira 2009) arvioituna. Korjuun riskit ovat yksi satovaihtelun aiheuttaja. Suomessa ja Ruotsissa timotein siemensato ohjeistetaan korjattavaksi suoralla leikkuupuinnilla (kts. Yllö ja Talvitie 1967, Järvenpää 1988 ja Lundin 1994). Lundinin (1994) mukaan suora leikkuupuinti on suosituin korjuutekniikka etenkin tilanteissa, joissa puintioljella on merkittävä arvo. Niemeläisen (1994) tutkimuksessa suora leikkuupuinti oli sopivin menettely nurminadan puintiin ja käytännöllinen myös timotein korjuuseen. Tulosten perusteella luo'olle niiton arvioitiin varmentavan sadon korjuuta tilanteessa, jossa on uhka varisemista kiihdyttävästä voimakkaasta tuulesta tai sateesta. Tanskalaisissa ohjeistuksissa (kts. Olsen 1988) timotei siemennurmi ohjeistetaan korjattavaksi niittämälle ensin karholle kun tuleentumisessa pisimmälle edenneiden tähkien kärjestä alkaa varista siemeniä. Karholleniittokoneeksi Olsen (1988) suositteli itsekulkevaa 10-12 jalan karholleniittokonetta. Niittosänki tulisi jättää sangen korkeaksi, koska silloin kuivuminen tapahtuu nopeammin ja nurmen läpikasvu karheen läpi estyy. Kuivuminen kestää 10-14 vrk riippuen karheen paksuudesta. Oregonissa, Yhdysvalloissa, siemennurmet korjataan Silbersteinin ym. (2007) mukaan pääsääntöisesti kahdessa vaiheessa varisemistappioiden minimoimiseksi - niittämällä karheelle kuivumaan viikoksi, ja puidaan sen jälkeen. Luo'olle niitetty kasvusto "jälkituleentuu" puintivalmiiksi. Luo'olle niitetty kasvusto ei ole niin altis tuulen ja sateen varistamisvaikutukselle kuin pystyssä oleva kasvusto. Suomeenkin on hankittu ensimmäisiä luo'olle niittolaitteita. Oletamme että luo'olle niitolla voidaan sekä kohottaa saatavan siemensadon määrää että vähentää satovaihtelua koska suuret varisemistappiot voidaan välttää. Pitkien sääennusteiden kehittyminen parantaa mahdollisuuksia luo'olle niiton ja puinnin ajoittamiseen.

\section{Aineisto ja menetelmät}

Koe toteutettiin Ylistarolla vuosina 2006 ja 2007. Kokeen toteutti MTT:n Etelä-Pohjanmaan tutkimusaseman henkilöstö maatilakokeena vuonna 2006 ja tutkimusaseman kenttäkokeena v. 2007. Kasvuston luo'olle niitto tehtiin sormiteräisellä niittokoneella, jonka työleveys oli 1,5 m. Puinti ja luo'olta puinti tehtiin Wintersteiger koeruutupuimurilla. Luo'olle niitetty kasvusto puitiin sängen päältä.

Koejäsenet olivat seuraavat:

1) Aikainen leikkuupuinti ajankohta I (ja luo’olle niitto koejäsenissä 3 ja 4)

2) Normaalin leikkuupuinnin ajankohta

3) Niitto luo'olle ajankohtana I ja luon puinti sängeltä koeruutupuimurilla 3-6 päivää niitosta

4) Niitto luo'olle ajankohtana I ja puinti sängeltä koeruutupuimurilla puinti 6-9 päivää niitosta

5) Puinti kahteen kertaan. Ensimmäinen puinti ajankohtana I hellävaraisin säädöin ja uudelleen puinti 6 vrk ensimmäisestä puinnista.

Koe oli lohkoittain satunnaistettu ja kokeessa oli neljä kerrannetta. Ohessa eri korjuukäsittelyjen ajankohdat vuosina 2006 ja 2007.

$\begin{array}{lllll} & \text { v. } 2006 & & \text { v. } 2007 & \\ \text { Koejäsen } & \text { Niitto/puinti } & \text { 2. puinti } & \text { Niitto/puinti } & \text { 2. puinti } \\ \text { 1) } & 15.8 .2006 & - & 20.8 .2007 & - \\ \text { 2) } & 21.8 .2006 & - & 26.8 .2007 & - \\ 3) & 15.8 .2006 & 21.8 .2006 & 20.8 .2007 & 23.8 .2007 \\ 4) & 15.8 .2006 & 24.8 .2006 & 20.8 .2007 & 26.8 .2007 \\ 5) & 15.8 .2006 & 21.8 .2006 & 20.8 .2007 & 26.8 .2007\end{array}$

Vuoden 2007 sadosta tehtiin ruuduittaiset puintikosteus, itävyys- ja tuhannen siemenen painon määritykset. Vuoden 2006 sadosta ao. määritykset tehtiin koejäsenittäin. 


\section{Sääolosuhteet korjuun aikana:}

Tehoisan lämpötilan summan kertymä korjuun alkaessa oli 15.8.2006 1041 astetta ja 20.8.2007 1039 astetta. Vuonna 2006 satoi päivittäin 1- 4 mm neljänä ensimmäisenä päivänä luo'olle niiton jälkeen, yhteensä 9,2 mm. Loppuajanjakso oli poutainen. Vuorokauden keskilämpötila vaihteli välillä 16,2 20,0 astetta. Tuulen nopeus oli 1-3 m/s ja vuorokauden suhteellisen kosteuden keskiarvo vaihteli välillä 41-74 \%. Vuonna 2007 luo'olle niitosta (20.8.) oli poutaa ensimmäiseen luo'olta puintiin (23.8.), mutta 24.8. satoi $2,3 \mathrm{~mm}$ ja $0,6 \mathrm{~mm} 25.8$. Suurempi sade $(4,5 \mathrm{~mm})$ tuli 26.8., mutta kasvustot puitiin ennen ao. sadetta. Vuonna 2007 vuorokauden keskilämpötila vaihteli välillä 14,6 - 17,0 astetta, ja korjuupäivän 26.8. keskilämpötila oli 11,8 astetta ja maksimilämpötila 16,1 astetta. Tuulen nopeus oli 1-6 m/s ja vuorokauden suhteellisen kosteuden keskiarvo vaihteli välillä 47-80 \%.

\section{Tulokset ja tulosten tarkastelu}

Kuvassa 1 esitetään koejäsenittäin siemensadon kokonaismäärä $\mathrm{kg} / \mathrm{ha}$. Koejäsenessä 5 on mukana uusintapuinnissa saatu sato. Uusintapuinnissa saatu sato oli v. 2006 noin $50 \mathrm{~kg} / \mathrm{ha} \mathrm{ja} \mathrm{v.} 2007$ noin 20 $\mathrm{kg} / \mathrm{ha}$. Vuosien välillä oli huomattava satoero. Vuonna 2006 saatiin normaalilla leikkuupuinnilla 502 $\mathrm{kg} / \mathrm{ha}$ ja vuonna $2007274 \mathrm{~kg} / \mathrm{ha}$. Molempina vuosina kokeessa saatu hehtaarisato oli hieman alhaisempi kuin Eviran siementilastoista laskettu keskisato Suomen kaupallisilla siemenviljelyksillä. Eviran siementuotannon vuosivaihtelun tilastosta laskettu keskisato oli v. $2006584 \mathrm{~kg} / \mathrm{ha} \mathrm{ja} \mathrm{v.} 2007$ $375 \mathrm{~kg} / \mathrm{ha}$.

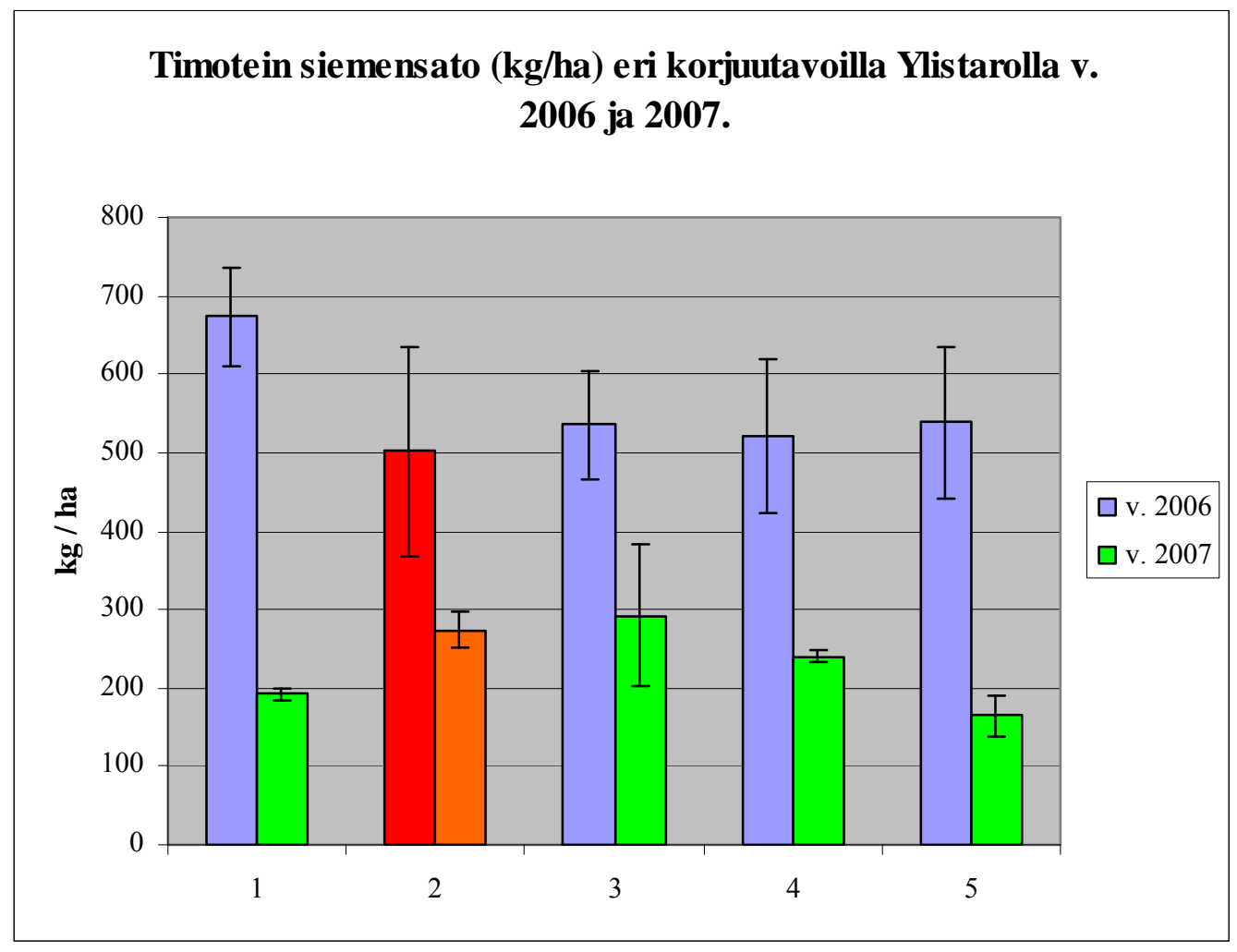

Kuva 1. Timotein siemensadot (kg/ha) korjuutapakokeessa vuosina 2006 ja 2007 Ylistarolla. Koejäsenet: 1) Varhainen suora leikkuupuinti, 2) Suora leikkuupuinti normaalina ajankohtana, 3) Luo'olle niitto varhaisen puinnin aikaan ja puinti luo'olta 3-6 vrk kuluttua, 4) Luo'olle niitto varhaisen puinnin aikaan ja puinti luo'olta 6-9 vrk:n kulutta, 5) Suora leikkuupuinti hellävaraisin säädöin varhaisena ajankohtana ja uudelleen puinti. Jana kuvaa keskihajonnan suuruutta. 
Vuonna 2006 suurin sato saatiin aikaisella ankaralla leikkuupuinnilla $673 \mathrm{~kg} / \mathrm{ha}$. Se erosi tilastollisesti merkitsevästi muista koejäsenistä joiden sato vaihteli välillä $502 \mathrm{~kg} / \mathrm{ha}$ (2) ja $538 \mathrm{~kg} / \mathrm{ha} \mathrm{(5).} \mathrm{Vuonna}$ 2007 koejäsenten 2, 3, ja 4 sadon määrä ei eronnut merkitsevästi toisistaan (274, 292 ja $240 \mathrm{~kg} / \mathrm{ha})$, mutta koejäsenten 1 ja 5 sato jäi tilastollisesti merkitsevästi alhaisemmaksi (192 ja $164 \mathrm{~kg} / \mathrm{ha})$. Sekä aikaisessa että normaalin aikaan tehdyssä leikkuupuinnissa siemenkoko oli v. 2007 merkittävästi alhaisempi kuin muissa koejäsenissä.

Vuonna 2006 tehtiin vain koejäsenkohtainen puintikosteusmääritys. Puintikosteudet olivat 1 ja 5 23,1\%, 2 20,3\%, 3 17,4\% ja 4 12,8\%. Vuonna 2006 luo'olla kuivattaminen näytti alentavan puintikosteutta ja siten kuivatustarvetta (Kuva 2). Vuonna 2007 puintikosteusmääritykset tehtiin ruuduittain. Vuonna 2007 puintikosteus oli merkitsevästi alhaisempi kolme päivää luo'olla kuivatetussa kasvustossa $16,4 \%$ kuin 2 :ssa $24,0 \%$, joka myös erosi merkitsevästi muiden koejäsenten puintikosteudesta (1 29,2\%, 4 28,3\% ja 5 27,8\%.) Korjuuajanjakson loppuosan sateisuus v. 2007 vaikutti tuloksiin.

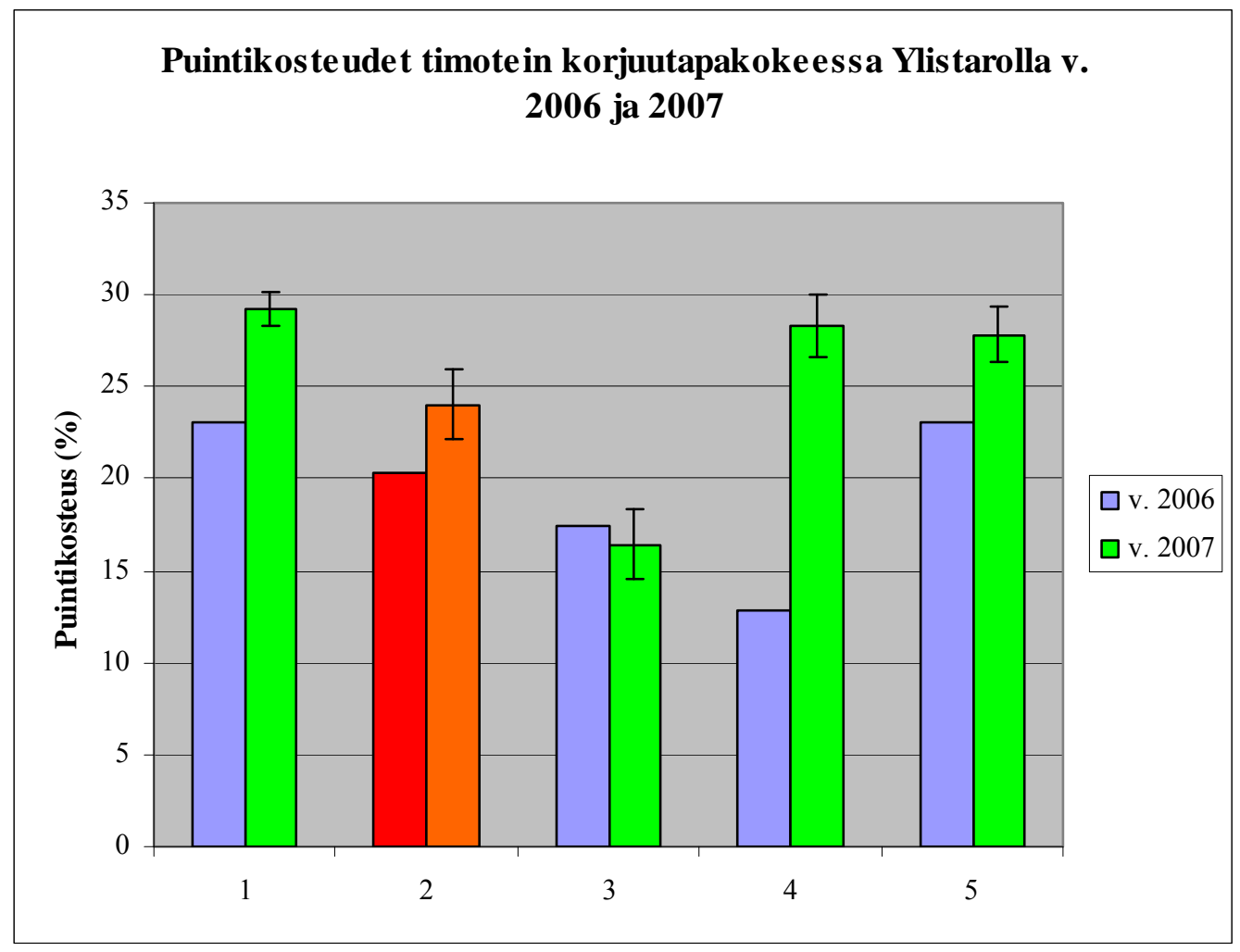

Kuva 2. Puintikosteus timotein siemensadon puinnissa (\%) korjuutapakokeessa vuosina 2006 ja 2007 Ylistarolla. Koejäsenet: 1) Varhainen suora leikkuupuinti, 2) Suora leikkuupuinti normaalina ajankohtana, 3) Luo'olle niitto varhaisen puinnin aikaan ja puinti luo'olta 3-6 vrk kuluttua, 4) Luo'olle niitto varhaisen puinnin aikaan ja puinti luo'olta 6-9 vrk:n kulutta, 5) Suora leikkuupuinti hellävaraisin säädöin varhaisena ajankohtana ja uudelleen puinti. Jana kuvaa keskihajonnan suuruutta.

Vuoden 2007 sadosta tehtiin ruuduittaiset itävyys- ja tuhannen siemenen painon määritykset. Tuhannen siemenen paino oli tilastollisesti merkitsevästi pienempi koejäsenissä 1 ja 2 (molemmissa $0,48 \mathrm{~g})$ kuin koejäsenessä 3 (0,72 g), 4 (0,66 g) ja 5 (0,69 g). Itävyys oli v. 2007 korkea kaikissa korjuumenettelyissä, myös varhaisessa korjuussa vaikka sen itävyys $94 \%$ poikkesikin tilastollisesti merkitsevästi muista koejäsenistä (itävyydet 96-97 \%) paitsi normaalista leikkuupuinnista (95\%). 


\section{Johtopäätökset}

Tutkimus antoi viitteitä, että timotein siemenkasvuston luo'olle niitolla voidaan saavuttaa tietyissä olosuhteissa etua sadon määrässä ja kuivatustarpeessa normaaliin suoraan leikkuupuintiin verrattuna. Tutkimukset varsinaisella korjuukalustolla ja erilaisissa korjuuolosuhteissa ja kasvustoissa ovat tarpeen tarkempien ohjeistusten tekemiseksi. Normaali suora leikkuupuinti antoi tässä kokeessa kuitenkin hyvän tuloksen käytettyihin luo'olta puintikäsittelyihin verrattuna. Puinti kahteen kertaan ei tuottanut lisäsatoa tässä tutkimuksessa.

\section{Kiitokset}

Kirjoittajat kiittävät Oiva Kuusiston säätiötä tutkimuksen toteuttamiseen saadusta tuesta.

\section{Kirjallisuus}

Evira. 2009. Siementuotannon vuosivaihtelu 1989-2008. Saatavilla.

http://www.evira.fi/attachments/kasvintuotanto_ja_rehut/siemenet/siemen_tilastot/siem_vv89-08.pdf

Järvenpää, M. 1988. Siemensadon puinti. In: Nurmikasvien siementuotanto. Tieto tuottamaan 49. pp. 63-73.

Lundin, G. 1994. Skördetröskning av vallfrögrödor. Teoksessa: Fröproduktion. NJF-seminarium nr. 241. Jokioinen, Finland, 28.-30.6.1994. NJF-Utredning/rapport nr 97. pp. 137-145.

Niemeläinen, O. 1994. Harvesting methods for herbage seed crops in Finland. Teoksessa: Fröproduktion. NJF-seminarium nr. 241. Jokioinen, Finland, 28.-30.6.1994. NJF-Utredning/rapport nr 97. pp. 223-229.

Olsen, F. 1988. Timothe (Phleum pratense). Teoksessa: Avl af markfró. Toimittaja: Torben Borggaard. Det kgl. danske Landhusholdningsselskab. pp. 31-35.

Silberstein, T.B., M. E. Mellbye, W. C. Young III \& T. G. Chastain. 2007. Using seed moisture to determine optimum swathing time in annual ryegrass (Lolium multiflorum Lam. seed production. Bioforsk Fokus Vol. 2, No. 12. 2007. pp. 270-273.

Yllö, L. \& H. Talvitie 1967. Tutkimuksia timotein leikkuupuinnista. Annales Agriculturae Fenniae 6: $81-96$. 